\title{
Effectiveness of performance appraisal on performance of employees
}

\author{
Muhammad Zohaib Abbas
}

\section{INTRODUCTION}

Performance appraisal is often regarded as the most critical function of human resource management (Selvarajan and Cloninger, 2008; Smither and London, 2009). Several prior studies have revealed that suggested that effective performance appraisal system is the sign of integral component of effectiveness of human resource management of an organization (Zapata-Phelan et al., 2009). Performance appraisal has been studied widely in several organizations in the western context. However, this particular topic has not been researched appropriately in the Asian context specifically in perspective of Pakistan. Selvarajan and Cloninger (2009) have also noted that performance appraisal is not effectively developed process within Pakistani organizations, but the evidence and prior literature on this topic is rare. Moreover, the prior literature on this subject aims at observational aspects and little emphasis is made on the empirical findings of the effectiveness of performance appraisal and its influence on employee performance (Selvarajan and Cloninger, 2008). Clearly, there is need to derive empirical findings on evaluation on effectiveness of performance appraisal system and its influence on employee performance in the context of Pakistan.

DeNisi and Pritchard (2006) have also noted that extant research on performance appraisal has excessively emphasized on psychometric issues rather than focusing on rigorous and systematic approach to performance appraisal that is more likely to enhance motivation level of employees for improving their performance. Roberson and Stewart (2006) found that employees respond to performance appraisal system in three perspectives that are: a) perception of fairness, b) perception of accuracy, and c) performance appraisal satisfaction. On the other hand, Selvarajan and Cloninger (2009) were of the view that performance appraisal provides consistent feedback to employees that enables them to improve performance. Thus, a critical issue in this regard is to assess and determine the factors that can influence outcomes of performance appraisal. In this respect, the current study aimed at the evaluation of critical factors associated with the effectiveness of performance appraisal system in Pakistan.

\section{Originality of research}

This paper has contributed to elaborate that how Pakistani organizations pursue performance appraisal system. In this way, gap in literature has been filled regarding performance appraisal in Pakistani organizations. The results of this study are based on the survey findings conducted with employees of several organizations. In this way, empirical contributions have been made by the researcher to elaborate effectiveness of performance appraisal system and its impact on performance of employees.

\subsection{Objectives}

The purpose of the study is to understand effectiveness of performance appraisal in the Pakistani organizations. Specifically, factors influencing performance appraisal have been identified in the study. Furthermore, this study also aimed to elaborate the influence of appraisal on employee performance in Pakistani organizations. Finally, critical challenges involved in the performance appraisal system will also be evaluated appropriately.

\section{Literature Review}

Employee performance appraisal is an effective tool or vehicle for assessment of employee performance and implementation of strategic initiatives for the improvement of employee performance (Lawler and McDermott, 2003). However, a considerable literature stream also suggests that there exist dissatisfaction in employees regarding performance appraisal system (Mercer, 2002; Roberson and Stewart, 2006; Moullakis, 2005). For instance, Morgan (2006) noticed that performance appraisal in many organizations has not met expectations of employees. In the same vein, prior findings by Smither and London (2009) have elucidated that 80-90\% managers reflect that performance appraisal has not been effective in improving employee and organization's performance.

Performance appraisal has been regarded as the most critical human resource function within organizations by which assessors or supervisors analyse and assess performance of their subordinates (Keeping 
and Levy, 2000). the outcomes of performance appraisal assists mangers to select specific pay rates, promotional decisions, development and training needs and motivational factors for employees (Zapata-Phelan et al., 2009). In this regard, performance appraisal system has been widely researched within organizational psychology to assess employee performance. However, despite of resources applied and attention made to this particular topic, prior researchers have found continuing dissatisfaction among employers and employees about outcomes of performance appraisal systems in terms of unfair, inaccurate and political outcomes (Rao, 2004; DeNisi and Pritchard, 2006). Therefore, it is important to study the factors affecting outcomes of performance appraisal system.

Literature has identified several indicators that affect the outcomes of performance appraisal system. In this regard, one critical factor is the appraisal source. This factor suggests that employee performance can be evaluated through multiple sources such as supervisors, managers, self, peers and even customers (Wood and Marshall, 2008). Another important characteristic of performance appraisal is the purpose for which performance has been appraised or evaluated (Thurston, 2001), and typically, performance appraisal systems are utilized for multiple purposes ranging from developmental and administrative purposes. Feedback richness is also an effective indicator that may affect the outcomes of performance appraisal. Feedback richness elaborates the specific appraisal environment by which frequent, specific and timely feedback is provided by employees to employers regarding job (Kinicki et al., 2004). Perceived accuracy of performance appraisal has been regarded as an important aspect to evaluate the satisfaction and motivation in employees in relation to performance appraisal (Wood and Marshall, 2008; and Selvarajan and Cloninger, 2009). In this regard, prior studies suggest that if employee perceive that appraisal outcomes are accurate, they are more likely to recognize these results and act on them (Roberson and Stewart, 2006).

On the other hand, employee perception of fairness also measures effectiveness of performance appraisal outcomes (Youngcourt et al., 2007). In this respect, previous studies have suggested that justice or fairness of performance appraisal can be evaluated into three dimensions. These are distributive, interactional fairness and procedural (Colquitt et al.

2001). In this regard, distributive fairness represents the extent to which outcomes of appraisal are distributed fairly (Smither and London 2009). In the appraisal context, the distributive context relates with the ratings of performance appraisal gained by employees. On the other hand, procedural fairness aims at the extent to which procedures deployed by organization for appraisal are fair in deriving outcomes of appraisal (ZapataPhelan et al., 2009). Contrary to this, the concept of interactional fairness represents the extent to which employees receive treatment of peers and supervisors during the process of appraising performance (Roberson and Stewart, 2006). Prior studies about meta-analysis of performance appraisal and perceptions of justice suggest that it enhances performance and satisfaction of employees (Roberson and Stewart, 2006). On the contrary, appraisal satisfaction represents the contentment of employees with the results of appraisal system. Levy and Williams (2004) suggest that analyzing employee satisfaction is important as it determines reactions of employees towards appraisal. Contrary to this, motivation represents the degree to which employees are willing to make improvements in their performance (Roberson and Stewart, 2006). Some authors suggest that perceptions about fairness hold a critical importance within organizations because it avoids negative outcomes such as disruptive behaviors and employee turnover and also enhance positive outcomes of organizations such positive citizenship, commitment and satisfaction with the job (Selvarajan and Cloninger, 2009).

Thurston (2001) has addressed the specific aspects related with performance appraisal and also reveal that effectiveness and success of appraisal system depends on reactions and feedback of employees. This suggests that employee feedback is critical factor in assessing effectiveness of appraisal system. This feedback can be positive or negative regarding outcomes of appraisal system. Prior studies have revealed that positive feedback is more likely to be accepted whereas employees often hesitate to accept negative outcomes of appraisal system (Rao, 2004). On the other hand, Roberson and Stewart (2006) suggest that if negative feedback is delivered in an effective and persuasive manner, employees will take it seriously and will focus on eliminating the negative aspects in their performance.

Prior literature has suggested that performance appraisal is an effective system for attaining different objectives. In this regard, Selvarajan and Cloninger (2009) have revealed that effective performance appraisal system results in improving performance of employees and motivating them. In this regard, it can be identified who are the weak performers and who strong performers within organizations are. In the same line of thought, prior studies have identified five major outcomes of effective performance appraisal (Rao, 2004). These are: 1) using results of performance appraisal to improve employee performance, 2) enhancing motivation, 3) reducing employee turnover, 4) associating rewards and employee performance and 5) establishing equity among employees (Rao, 2004; Selvarajan and Cloninger, 2009).

Nurse (2005) has also discussed the impact of appraisal on employees and organizations. He specifically suggested that results of appraisal provide information to managers to take further steps about promotions and development of employees. On the contrary, Rao (2004) suggests that weak areas of 
performance are identified through effective performance appraisal system. In this way, managers can take decisions regarding training of employees to improve those weak areas. Moving further, Teratanavat, Raitano and Kleiner (2006) suggest that effective performance appraisal results in reducing stress level of employees. In this way, performance appraisal system interlinks current, past and future performance of employees.

\section{Theoretical Framework}

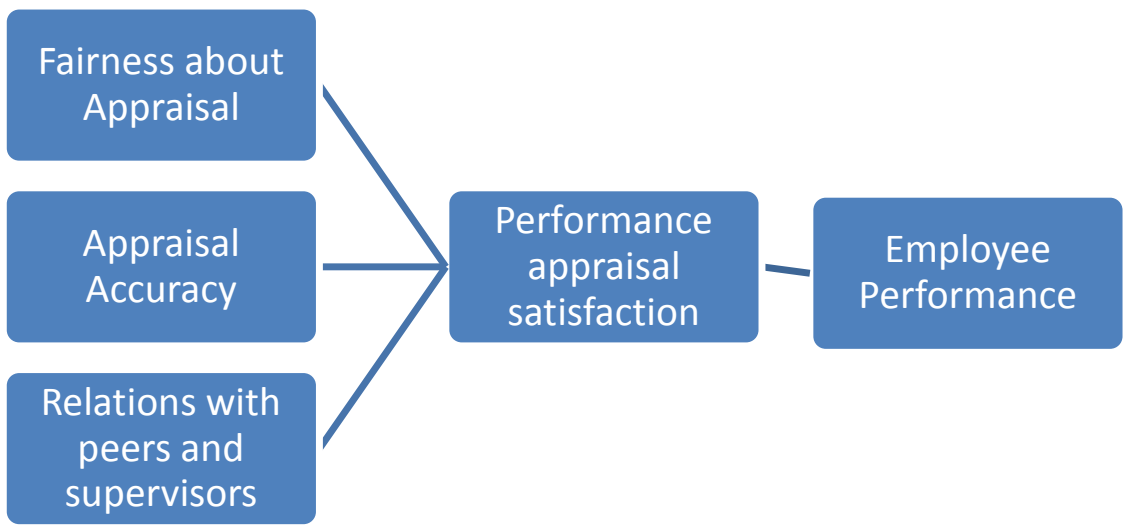

IV. Type of Research

The study has been conducted to analyse that how effective is performance appraisal in Pakistani organizations. For this reason, quantitative analysis has been used to describe the research problem. In this respect, quantitative analysis and data collection tools are used to describe quantitative analysis between performance appraisal and employee performance. The quantitative research has provided empirical investigation about research purpose regarding effectiveness of performance appraisal and performance of employees in Pakistani organizations.

\subsection{Type of Data}

In this study, primary and secondary data have been used for investigating effectiveness of performance appraisal within Pakistani organizations. The secondary data was used to know what prior researchers have theorized about performance appraisal and employee performance. This data provided theoretical investigation of research problem. On the other hand, primary data was used to get empirical investigation about effectiveness of performance appraisal and its influence on employee performance in Pakistani organizations.

\subsection{Data Collection Method}

In this particular study, survey method was used for collecting primary data from employees of different organizations within Pakistan. For collecting primary data, close ended questionnaire was used. This questionnaire was composed in two sections. The first section of questionnaire elaborated the demographical information about respondents whereas the second section highlighted critical factors of performance appraisal in Pakistan. On a scale of 1-5, effectiveness of performance appraisal was measured in this paper. For collecting data, self administered survey was conducted with the employees of the Pakistani organizations.

Quantitative data analysis was used in this study for investigating empirical analysis of research problem. In addition, statistical analysis was made to derive association between variables of the study.

\subsection{Sample and Population}

For collecting data, survey technique was used in this study. For this reason, a sample was used in the study. This sample was selected from different organizations of the Pakistan. This sample was selected from different industries i.e. banking, manufacturing and services. In this respect, non probability sampling technique was used in the study so that no preference can be made in the sample selection. On this basis of non probability sampling, a sample of 250 employees was selected from different organizations of Pakistan.

\section{Results and Analysis}


In this study, response rate of $83 \%$ was achieved that was adequate to analyse results to analyse effectiveness of appraisal. In this study, statistical analysis methods were used to get empirical evidence about impact of performance appraisal on employee performance.

The descriptive results of the study about gender of respondents revealed that $59 \%$ respondents were males whereas $41 \%$ were females. During the sample selection, no priority was made between male or female respondent. As far as the age of respondents is concerned, it was found that $17 \%$ respondents were less than 20 years old, $31 \%$ respondents were between $20-29$ years, $30 \%$ were between $30-39$ years, $19 \%$ were between 40 49 years and $3 \%$ were either 50 years old or above. When it comes to education level of respondents, the results revealed that $7 \%$ had primary education, $20 \%$ were intermediates, $41 \%$ graduates and $20 \%$ either had masters level or higher education level. The rest of the respondents had other technical level education.

When respondents were asked about the fact that had their performance been appraised ever, $100 \%$ respondents answered in yes and the rest of respondents answered in no. The frequency of appraisal suggested that yearly appraisal is more evident in organizations. 19\% respondents revealed that their performance is appraised monthly, 28\% respondents suggested that their performance is appraised quarterly. There have been $21 \%$ respondents who suggested that semi annually performance appraisal is conducted by organizations whereas $32 \%$ respondents revealed that yearly performance appraisal is followed in their organizations. When asked about performance appraisal mode, $11 \%$ respondents suggested that feedback mechanism is used to appraise performance. $40 \%$ respondents pointed out written statement method, $28 \%$ pointed out at ranking method and rest of the respondents highlighted face to face discussions for appraisal.

\subsection{Descriptive results}

For analyzing the effectiveness of performance appraisal system in Pakistani context, the data has been analyzed descriptively. The descriptive results of study have been elaborated as below:

\begin{tabular}{|l|l|l|l|l|}
\hline & & & Standard & Standard \\
\hline Variables & $\mathrm{N}$ & Mean & deviation & error mean \\
\hline & & & & \\
\hline Fairness about Appraisal & 240 & 25.26 & 2.35 & 0.225 \\
\hline Appraisal Accuracy & 240 & 19.13 & 1.74 & 0.165 \\
\hline Relations with peers and supervisors & 240 & 24.84 & 2.26 & 0.215 \\
\hline Performance appraisal satisfaction & 240 & 15.05 & 2.61 & 0.248 \\
\hline Employee Performance & 240 & 18.44 & 3.95 & 0.376 \\
\hline
\end{tabular}

\subsection{Regression Analysis}

To determine statistical analysis of the factors affecting effectiveness of performance appraisal in Pakistan, an independent t-test was conducted. The four variables evaluated perceptions of employees towards performance appraisal system in Pakistan and also evaluated influence of appraisal on employee performance. The findings revealed that there exist significant differences among respondents' opinions about perception of appraisal system. Here is the summarized statistical analysis for effectiveness of performance appraisal in Pakistan.

\begin{tabular}{lllllc} 
Variables & F & \multicolumn{2}{l}{ Significancet } & df & Significance (two-tailed) \\
\hline Fairness about Appraisal & 1.291 & 0.257 & 18.75 & 202.05 & 0.000 \\
Appraisal Accuracy & 99.490 & 0.000 & 13.18 & 337.85 & 0.000 \\
Relations with peers and supervisors & 0.847 & 0.358 & 0.467 & 229.59 & 0.641 \\
Performance appraisal satisfaction & 7.774 & 0.006 & 6.24 & 265.83 & 0.000 \\
Employee Performance & 4.782 & 0.029 & 5.06 & 213.28 & 0.000
\end{tabular}

The statistical analysis revealed that all variables except "Relations with peers and supervisors" have significant association with the performance of employees. In the above model, all values less than 0.05 represent significant level. In this regard, it has been concluded that performance appraisal in Pakistani context is related with the employee performance outcomes.

\section{Conclusion}

The study was based on the evaluation of effectiveness of performance appraisal in Pakistani organizations. The study was conducted through survey analysis conducted with the employees of Pakistani organizations. On the basis of statistical analysis, it has been concluded that performance appraisal is linked 
with the employee performance outcomes in Pakistani organizations. In addition to this, the results also reflect that all study variables are significant except relationship among peers and supervisors regarding performance appraisal process.

The results of the study provide sound understanding about that employees have fair perception about performance appraisal. This also reveals that respondents think that performance appraisal outcomes are accurate and significant towards employee performance. In addition, the study outcomes also reflect that performance appraisal impacts performance level of employees in organizations.

The future prospects of study reveal that its generalizability is low because of a small sample. Therefore, future researchers have option of expanding the scope of study by using the large and diverse sample. In addition, they can also highlight differences in performance appraisal followed in different industries of Pakistan.

\section{References}

[1]. Colquitt J.A., Conlon D.E., Wesson M.J., Porter H., and Ng, K.Y. (2001), 'Justice at the Millennium: A Meta-Analytic Review of 25 Years of Organizational Justice Research,' Journal of Applied Psychology, Vol. 3, pp. 425-445.

[2]. DeNisi A., and Pritchard R. (2006), 'Performance Appraisal, Performance Management and Improving Individual Performance: A Motivational Framework,' Management and Organization Review, Vol. 2, No. 2, pp. 253-277.

[3]. Kinicki A.J., Prussia G.E., Bin W., and McKee-Ryan F.M. (2004), 'A Covariance Structure Analysis of Employees' Response to Performance Feedback,’ Journal of Applied Psychology, Vol. 89, No. 6, Pp. 1057-1069.

[4]. Keeping L.M., and Levy P.E. (2000), Performance Appraisal Reactions: Measurement, Modeling, and Method Bias,' Journal of Applied Psychology, Vol. 85, No. 5, pp. 708-723.

[5]. Lawler E.E., and McDermott M. (2003), 'Current Performance Management Practices: Examining the Varying Impacts,' Wold at Work Journal, Vol. 12, No. 2, pp. 49-60

[6]. Levy P.E., and Williams J.R. (2004), 'The Social Context of Performance Appraisal: A Review and Framework for the Future,' Journal of Management, Vol. 30, No. 6,pp. 881-905.

[7]. Mercer (2002), Effective Performance Management Practices, New York: Mercer Human Resource Consulting.

[8]. Morgan R. (2006), 'Making the Most of Performance Management Systems,' Compensation and Benefits Review, Vol. 38, pp. $22-27$.

[9]. Moullakis J. (2005), 'One in Five Workers "Actively Disengaged”,' The Australian Financial Review, Vol. 10

[10]. Nurse L. (2005). Performance appraisal, employee development and organizational justice: exploring the linkages. The International Journal of Human Resource Management, Vol. 16(7), pp. 1176 - 1194

[11]. Roberson Q.M., and Stewart M.M. (2006), 'Understanding the Motivational Effects of Procedural and Informational Justice in Feedback Processes,' British Journal of Psychology, Vol. 97, No. 3, pp. 281-298.

[12]. Rao T.V. (2004), Performance Management and Appraisal Systems; HR Tools for Global competitiveness, New Delhi: Response Books (A division of Sage Publications)

[13]. Selvarajan R., and Cloninger P.A. (2008), 'The Importance of Accurate Performance Appraisals for Creating Ethical Organizations,' Journal of Applied Business Research, 3rd quarter, Vol. 24, No. 3, pp. 39-44.

[14]. Selvarajan T.T., and Cloninger, P.A. (2009), 'The Influence of Job Performance Outcomes on Ethical Assessments,' Personnel Review, Vol. 38, No. 4, pp. 398-412.

[15]. Smither, J.W., and London, M. (2009), 'Best Practices in Performance Management,' in Performance Management: Putting Research into Action, eds. J.W. Smither and M. London, San Francisco, CA: Jossey-Bass

[16]. Thurston, P.W. Jr. (2001), 'Clarifying the structure of justice using fairness perceptions of Performance Appraisal practices,' unpublished Ph.D. dissertation, Albany, NY.

[17]. Teratanavat, R., Raitano, R., \& Kleiner, B. (2006). How to Reduce Employee Stress. Nonprofit World, Vol. 24(3), pp. 22 - 24

[18]. Wood, R.E., and Marshall, V. (2008), 'Accuracy and Effectiveness in Appraisal Outcomes: The Influence of Self-Efficacy, Personal Factors and Organisational Variables,' Human Resource Management Journal, Vol. 18, No. 3, pp. 295-313

[19]. Youngcourt, S.S., Leiva, P.I., and Jones, R.G. (2007), 'Perceived Purposes of Performance Appraisal: Correlates of Individualand Position-Focused Purposes on Attitudinal Outcomes,' Human Resource Development Quarterly, Vol. 18, No. 3, pp. 315343.

[20]. Zapata-Phelan, C., Colquitt, J., Scott, B., and Livingston, B. (2009), 'Procedural Justice, Interactional Justice, and Task Performance: The Mediating Role of Intrinsic Motivation,' Organizational Behavior and Human Decision Processes, Vol. 108, No. 1, pp. 93-105

\section{Appendix}

\section{Please mention your gender level}

a) Male

b) Female

\section{Please mention your age range}

a) $\quad 20$ years

b) $\quad 20-29$ Years

c) $\quad 30-39$ Years

d) $\quad 40-49$ Years

e) 50 and above

\section{Please mention your education level:}

a) Primary

b) Intermediate

c) Graduation

d) Masters and higher than Masters Degree 


\section{e) Others}

\section{Regarding Performance Appraisal}

1. Have you ever been appraised within organization? (If yes, answer all questions below)

a) Yes

b) No

2. How frequently your performance is appraised?

a) Monthly

b) Quarterly

c) Semi annually

d) Yearly

3. Which of the method(s) is used for appraising your performance?

a) Ranking method

b) Face to face discussions

c) Feedback mechanism

d) Written Statement method

e) Others (Specify)

On the basis of your prior experience regarding performance appraisal system, please answer following questions on the scale: ( $1=$ strongly agree, $2=$ agree, $3=$ neutral, $4=$ disagree and $5=$ strongly disagree $)$

\begin{tabular}{|c|c|c|c|c|}
\hline & \begin{tabular}{l|l}
1 & 2 \\
\end{tabular} & 3 & 4 & 5 \\
\hline \multicolumn{5}{|l|}{ Fairness about Appraisal } \\
\hline \multicolumn{5}{|l|}{ The results of appraisal are fair } \\
\hline \multicolumn{5}{|l|}{ Assessors appraise performance without any biasness } \\
\hline \multicolumn{5}{|l|}{ Any other employee is not prioritized during performance appraisal system } \\
\hline \multicolumn{5}{|l|}{ Appraisers treat you fairly during performance appraisal process } \\
\hline \multicolumn{5}{|l|}{ Appraisal Accuracy } \\
\hline \multicolumn{5}{|l|}{ Appraisal outcomes are accurate } \\
\hline \multicolumn{5}{|l|}{ Minimum errors are identified in the appraisal system } \\
\hline \multicolumn{5}{|l|}{ The reliability of results of appraisal system are high } \\
\hline \multicolumn{5}{|l|}{ Relations with peers and supervisors } \\
\hline \multicolumn{5}{|l|}{ You are allowed to discuss appraisal results with supervisors } \\
\hline \multicolumn{5}{|l|}{ You are allowed to deliver feedback to management regarding appraisal results } \\
\hline \multicolumn{5}{|l|}{ Interaction between you and management enhances appraisal effectiveness } \\
\hline \multicolumn{5}{|l|}{ Interaction with supervisors and management also enhances your motivation } \\
\hline \multicolumn{5}{|l|}{ Performance appraisal satisfaction } \\
\hline \multicolumn{5}{|l|}{ You are satisfied with the outcomes of appraisal } \\
\hline \multicolumn{5}{|l|}{ You are satisfied with the way by which your performance is appraised } \\
\hline \multicolumn{5}{|l|}{ You think that current appraisal system has limitations } \\
\hline \multicolumn{5}{|l|}{ Employee Performance } \\
\hline \multicolumn{5}{|l|}{ Performance appraisal has provided opportunity to improve performance } \\
\hline \multicolumn{5}{|l|}{ Your motivation has increased through appraisal outcomes } \\
\hline \multicolumn{5}{|l|}{$\begin{array}{l}\text { Appraisal outcomes have given you opportunity to eliminate weak areas in } \\
\text { performance }\end{array}$} \\
\hline \multicolumn{5}{|l|}{ You think that training delivered after appraisal will improve your performance } \\
\hline You have noticed no change in your performance through appraisal system & & & & \\
\hline
\end{tabular}

